\title{
Numerical Study of a Tangentially Fired Boiler for Reducing Steam Tube Overheating
}

\author{
Guangwu Tang \\ Center for Innovation through Visualization and \\ Simulation, \\ Purdue University Calumet \\ 2200 169th Street \\ Hammond, IN, 46323 \\ 219-671-3423 Email:tang@purduecal.edu \\ Kurt Johnson \\ ArcelorMittal, \\ Global Research and Development, \\ 3001 E. Columbus Drive, \\ East Chicago, IN, 46312 \\ 219-399-6513 Email: Kurt.Johnson@arcelormittal.com

\section{Dong Fu} \\ Center for Innovation through Visualization and \\ Simulation, \\ Purdue University Calumet \\ 2200 169th Street \\ Hammond, IN, 46323 \\ 219-989-3157 Email: fudong1985@gmail.com
}

\author{
Bin Wu \\ Center for Innovation through Visualization and \\ Simulation, \\ Purdue University Calumet \\ 2200 169th Street \\ Hammond, IN, 46323 \\ 219-801-5397 Email:bin.wu@purduecal.edu \\ Albert Kirk \\ ArcelorMittal-Burns Harbor, \\ 250 U.S. 12 , \\ Burns Harbor, IN, 46312 \\ 219-787-3446 Email: Albert.Kirk@arcelormittal.com
}

Chenn Q. Zhou (Corresponding Author)

Center for Innovation through Visualization and Simulation,

Purdue University Calumet

2200 169th Street

Hammond, IN, 46323

219-256-2665 Email: czhou@purduecal.edu 
Abstract: A comprehensive numerical and experimental study on a $200 \mathrm{MW}$ tangentially fired boiler firing metallurgical gases was conducted. A three-dimensional Computational Fluid Dynamics (CFD) model was developed to simulate the flow characteristics and combustion process inside the boiler. The Eddy Dissipation Concept combustion model was applied to take into account detailed turbulent interactive reacting chemical reactions. Field experiments were also conducted on the original tangentially fired boiler under different operation conditions. Flame profiles videos were captured during experiments. A quick comparison of the experimental flame profile with numerical simulation results shows good agreement. Wall steam tubes overheating problem was observed, and the hot spots were identified based on a wide range of typical operation conditions. The effect of total fuel input and natural gas percentage on the furnace wall temperature were investigated.

Key Words: CFD, Tangentially Fired Boiler, Metallurgical Gases, Temperature Deviation. 
Numerical Study of a Tangentially Fired Boiler for Reducing Steam Tube Overheating

\section{Introduction}

Tangential fired boilers are widely used in modern industrial plants mainly for steam generation. Tangential fired boiler is also called corner-fired furnace [1], which is determined by its furnace shape and the position of the fuel/oxidizer inlet. It is normally with four sides and four corners where the fuel and air are supplied. During operation, the flames are directed tangentially connected and there is an imaginary circle in the center of the boiler created by the flow vortex [2]. The inside combustion with high temperature can dramatically expand the gas volume and lead the flue gas moving upwards with vortex combustion characteristics.

The advantages of using tangential fired boilers are obvious, such as good flame stability, good adaptability to different kinds of fuels and low NOx emissions [3,4]. However, there is a frequently reported problem of steam tube rupture. It is believed that the heat imbalance and gas temperature deviation both in the vertical combustion zone and the horizontal flue gas pass way are the main reasons caused the local overheating and steam tube failure with vapor leakage accidents on the wall [5]. In order to alleviate the steam tube overheating problem, further studies on the tangentially fired boilers are needed. Physical experiment method was an old but practical way engineers used to do to get better understanding of the boilers, but full scale measurements are restricted by the high risk and cost [6]. Collaborating with physical experiments, the numerical methods can help to conduct computational experiments effectively and safely.

Computational Fluid Dynamics is a process of replacing the complex Partial Differential Equations (PDCs) that govern the flow and reactions with a simpler system of algebraic equations, and then do calculations on the large amount of divided cells in a domain through iterations refer to boundary conditions. The CFD models can conduct experiments on computer at different operation conditions, and can help visualize the results both statistically and graphically [6-8]. Many researchers conducted numerical simulation on industrial tangentially fired boilers. Yuegui Zhou, et al $[3,4,9]$ studied the flow field in the upper furnace of a large scale tangentially fired boiler, they found that the flow field was apparently different on the left and right side of the upper part and the velocity deviation is large in horizontal flue gas pass, which was the main reason caused the operational accidents of large scale tangentially fired boilers, such as steam tube overheating and explosion of super heaters. Yin, et al [10] studied the flow, combustion, heat transfer and 
emissions of a 609 MW utility tangentially fired boiler by CFD and showed good agreement with design parameters and site operation records. Vuthaluru et al [11] modeled a large scale tangentially fired boiler by using CFD to predict the temperature deviation and particle trajectories.

Different industrial tangentially fired boiler may have different tasks, and accordingly have different fuel input. Pulverized coal is now playing an important role in industrial boilers as its cheap fuel price and high heating values. The research on modeling pulverized coal combustion is also dominant in CFD application on boilers. [12-14] However, as fossil fuels are consumed dramatically around the world, substituting a part of a valuable fuel like Natural Gas (NG) or coal by a less valuable fuel such as Blast Furnace Gas (BFG) and Coke Oven Gas (COG) in the industrial boilers is an economical and environmental method [15], especially for a steel mill. Some literatures have report mixing fuel systems such as BFG/coal [16], BFG/NG [17] and BFG/COG [18,19]. In steel industry, the low calorific value residual gases generated both in ironmaking and steelmaking process, such as BFG, COG and Linz Donawitz Gas (LDG), are utilized as supplemental fuels by furnaces within the steel plant especially boilers to generate steam to provide mechanical energy, thermal energy and electrical energy $[15,18,19]$.

The flow pattern and the combustion characteristics inside of the boilers are different under different fuel input. The BFG contains mainly nitrogen $\left(\mathrm{N}_{2}\right)$, with some carbon monoxide (CO) and carbon dioxide $\left(\mathrm{CO}_{2}\right)$, and little amount of hydrogen $\left(\mathrm{H}_{2}\right)$. The $\mathrm{COG}$ is composed mainly of hydrogen $\left(\mathrm{H}_{2}\right)$ and methane $\left(\mathrm{CH}_{4}\right)$. [15] Put low caloric value fuels into the tangentially fired boilers are frequently applied. Researchers are mainly focused on the efficiency and emissions when using these fuels.[20-23] However, the combustion characteristics with fuels (BFG and $\mathrm{COG}$ ) supplement for $\mathrm{CH}_{4}$ in the steel mill tangentially fired boilers are seldom reported. Through the motivation from a real industrial tangentially fired boiler in a steel mill facing steam tube failure problem, a detailed analysis of this type of boiler firing metallurgical gases is urgently needed and has a significant meaning.

Several CFD combustion models can be applied to simulate the combustion in the tangentially fire boiler. Based on different fuel input, combustion models for different boilers are varying from one to another. Mixture fraction probability density function (PDF) model was used for coal fired 
boilers. [24-26] Kim et al [27] investigated the fuel lean reburning process in a $1.5 \mathrm{MW}$ boiler which fired $\mathrm{CH}_{4}$ as fuel. The computational combustion model they used was eddy dissipation (ED) model and the results validated with the experiment data including temperature and species. Parente et al [28] studied the effect of combustion models and kinetic mechanisms on the moderate or intense low-oxygen dilution (MILD) combustion. The results show that eddy dissipation/finite rate $(\mathrm{ED} / \mathrm{FR})$ model was unable to capture the volumetric features. While, Eddy Dissipation Concept (EDC) model with detailed chemistry provides more realistic results. Furthermore, Hjertager et al [29-30] presented various turbulent combustion models including the eddydissipation concept model. They report that the standard eddy dissipation concept model with multiple time scale turbulent mixer model can give good results. The Eddy-Dissipation Concept Model is an extension of the Eddy-Dissipation Model to finite rate chemistry, which assumes reactions occur on small scales and calculates a volume fraction of small scale eddies. It is also include detailed chemical mechanisms in turbulence flows. [31]

Sidewall overheating can lead to steam tube failure and operation shutdown. Broken tubes have to be replaced and thorough inspection has to be conducted in order to reset the boiler unit. According to the observation through cameras mounted inside the boiler, the overheating is believed to be the accumulated results of long-term, flame impingement. In this paper, a detailed numerical simulation of an industrial boiler firing metallurgical gases was conducted.

\section{Methodology}

In this CFD model, detailed turbulent combustion flow with heat and mass transfer was presented. The eddy dissipation concept turbulence combustion model was used to calculate the combustion reactions. The realizable k- $\varepsilon$ turbulence model was applied to predict the flow turbulence. The P1 radiation model was used to take account of the dominant heat transfer flux.

\subsection{General Transport Equations:}

1 The Mass Conservation Equation (Continuity equation)

$$
\nabla \cdot(\rho \vec{v})=0
$$

2 The Momentum Conservation Equation

$$
\nabla \cdot(\rho \vec{v} \vec{v})=-\nabla_{p}+\nabla \cdot(\overline{\bar{\tau}})+\rho \bar{g}+\bar{F}
$$


Where $\overline{\bar{\tau}}$ is the stress tensor which is given by

$$
\overline{\bar{\tau}}=\mu\left[\left(\nabla \vec{v}+\nabla \vec{v}^{T}\right)-\frac{2}{3} \nabla \cdot \vec{v} I\right]
$$

By the long-time averaged method, Equation (2) can be converted to Reynolds-averaged NavierStokes (RANS) equation as follows [32]:

$$
\frac{\partial}{\partial x_{j}}\left(\rho u_{i} u_{j}\right)=-\frac{\partial p}{\partial x_{i}}+\frac{\partial}{\partial x_{i}}\left[\mu\left(\frac{\partial u_{i}}{\partial x_{j}}+\frac{\partial u_{j}}{\partial x_{i}}-\frac{2}{3} \sigma_{i j} \frac{\partial u_{I}}{\partial x_{I}}\right)\right]+\frac{\partial}{\partial x_{j}}\left(-\rho \overline{u_{\imath}^{\prime} u_{\jmath}^{\prime}}\right)
$$

In Equation (4), the Reynolds stresses may be related to the velocity gradient by Boussinesq hypothesis as follows:

$$
-\rho \overline{u_{\imath}^{\prime} u_{\jmath}^{\prime}}=\mu_{t}\left(\frac{\partial u_{i}}{\partial x_{j}}+\frac{\partial u_{j}}{\partial x_{i}}\right)-\frac{2}{3}\left(\rho k+\mu_{t} \frac{\partial u_{k}}{\partial x_{k}}\right) \sigma_{i j}
$$

3 The Energy Equation

$$
\nabla \cdot[\vec{v}(\rho E+P)]=\nabla \cdot\left[k_{e f f} \nabla T-\sum_{j} h_{j} \vec{J}_{j}+\left(\overline{\bar{\tau}}_{e f f} \cdot \vec{v}\right)\right]+S_{h}
$$

Where $\mathrm{E}$ is defined as:

$$
E=h-\frac{p}{\rho}+\frac{v^{2}}{2}
$$

Where sensible enthalpy $\mathrm{h}$ is defined for ideal gases as

$$
h=\sum_{j} Y_{j} h_{j}
$$

where $h_{j}$ is defined as

$$
h_{j}=\int_{298.15 K}^{T} C_{p, j} d T
$$

4 Turbulence Model

The gas flow pattern in the tangentially fired boiler after entering the burner shows high turbulence intensity characteristic as its vortex mixing mechanism. This turbulence phenomenon can be solved by time averaged velocity scalar. The averaged Reynolds stresses term can be solved through the conservation of kinetic energy and dissipation rate, which called the k- $\varepsilon$ turbulence model [33]. The Realizable k- $\varepsilon$ turbulence model is used due to its ability to model flow with strong streamline curvature, vortices and rotation. It is a semi-empirical model based on the transport equation for the turbulence energy $(k)$ expressed below respectively:

$$
\frac{\partial}{\partial t}(\rho k)+\frac{\partial}{\partial x_{i}}\left(\rho k u_{j}\right)=\frac{\partial}{\partial x_{i}}\left[\left(\mu+\frac{\mu_{t}}{\sigma_{k}}\right) \frac{\partial k}{\partial x_{i}}\right]+G_{k}+G_{b}-\rho \varepsilon-Y_{M}+S_{K}
$$




$$
\mu_{t}=c_{\mu} \rho \frac{k^{2}}{\varepsilon}
$$

The generation of kinetic energy and buoyance force attribution are:

$$
\begin{aligned}
G_{k} & =-\rho \overline{u_{\imath}^{\prime} u_{J}^{\prime}} \frac{\partial u_{j}}{\partial x_{i}} \\
G_{b} & =\beta g_{i} \frac{\mu_{t}}{P r_{t}} \frac{\partial T}{\partial x_{i}}
\end{aligned}
$$

The turbulent dissipation rate $(\epsilon)$

$$
\frac{\partial}{\partial t}(\rho \varepsilon)+\frac{\partial}{\partial x_{j}}\left(\rho \varepsilon u_{j}\right)=\frac{\partial}{\partial x_{j}}\left[\left(\mu+\frac{\mu_{t}}{\sigma_{\varepsilon}}\right) \frac{\partial \varepsilon}{\partial x_{i}}\right]+\rho C_{1} S \varepsilon-\rho C_{2} \frac{\varepsilon^{2}}{k+\sqrt{v \varepsilon}}+C_{1 \varepsilon} \frac{\varepsilon}{k} C_{3 \varepsilon} G_{b}+S_{\varepsilon}
$$

Where the equations are given on $x_{j}$ direction. $\mathrm{C}_{1}=\max \left(0.43, \frac{\mathrm{y}}{\mathrm{\eta}+5}\right), \mathrm{\eta}=\mathrm{s} \frac{k}{\varepsilon}, \mathrm{s}=\sqrt{2 S_{i j} S_{i j}}, S_{i j}=$ $\frac{1}{2}\left(\frac{\partial u_{j}}{\partial x_{i}}+\frac{\partial u_{i}}{\partial x_{j}}\right), \mathrm{C}_{2}$ and $\mathrm{C}_{1 \varepsilon}$ are constant.

\section{Species Conservation Equation}

During the operation process, the natural gas burns with the combustion air supplied from the burner, and the water evaporation happen in the high temperature circumstance. Therefore, species transport model can define the species and also calculate the species conservation and transportation. The local mass fraction of each species $Y_{i}$ can be solved by the convection-diffusion equations. The conservation equation of each species can be expressed by

$$
\begin{aligned}
& \nabla *\left(\rho \bar{v} Y_{i}\right)=-\nabla * \overrightarrow{J_{l}}+R_{i} \\
& \overrightarrow{J_{l}}=-\left(\rho D_{i, m}+\frac{\mu_{t}}{S c_{t}}\right) \nabla Y_{i}-D_{T, i} \frac{\nabla T}{T}
\end{aligned}
$$

\section{Combustion Model (Eddy Dissipation Concept)}

The detailed Arrhenius chemical reaction kinetics of natural gas combustion can be incorporated in turbulent flames through eddy-dissipation concept model [34]. EDC model relies on the Kolmogorov cascade of energy dissipation on all lengths scales in turbulence flow. The chemical reactions and molecular mixing were assumed associate with turbulence dissipation occurred in fine structure of the flow. The source terms in the conservation equation for the mean species, $i$ modeled as

$$
R_{i}=\frac{\rho\left(\xi^{*}\right)^{2}}{\tau^{*}\left[1-\left(\xi^{*}\right)^{3}\right]}\left(Y_{i}^{*}-Y_{i}\right)
$$


Numerical Study of a Tangentially Fired Boiler for Reducing Steam Tube Overheating

$$
\begin{gathered}
Y_{i}=\left(\xi^{*}\right)^{3} Y_{i}^{*}+\left(1-\left(\xi^{*}\right)^{3}\right) Y_{i}^{0} \\
\xi^{*}=C_{\xi}\left(\frac{v \varepsilon}{k^{2}}\right)^{1 / 4}
\end{gathered}
$$

The reactions are assumed to occur in the fine structures over a residence time scale $\tau^{*}$.

$$
\tau^{*}=C_{\tau}\left(\frac{v}{\varepsilon}\right)^{1 / 2}
$$

7 P1 Radiation Model

In the tangentially fired boiler, another heat transfer form is radiation due to the combustion occurred inside with high temperature around $2000 \mathrm{~K}$. Therefore, thermal radiation should be considered. Both discrete ordinate method and P1 model have been applied by previous researchers [35-36]. Ferreira [36] investigated two different numerical radiation methods to simulate a boiler and proposed that both the P1 approximation and Discrete Transfer Model are adequate for the radiation inside the boiler. The radiative heat flux as function of incident radiation intensity in P1 model is:

$$
q_{r}=-\frac{1}{3\left(a+\sigma_{s}\right)-C \sigma_{s}} \nabla G
$$

The transportation equation for incident radiation $G$ is:

$$
\begin{aligned}
& \nabla(\Gamma \nabla \mathrm{G})-\mathrm{aG}+4 \mathrm{a} n^{2} \sigma \mathrm{T}^{4}=S_{G} \\
& -\nabla q_{r}=a G-4 a n^{2} \sigma T^{4}
\end{aligned}
$$

The expression for $-\nabla q_{r}$ can be directly substitute into the energy equation to account for the heat sources due to the radiation.

\subsection{Simulation Code and Solution Method}

This simulation was conducted by the commercial software package ANSYS Fluent 13.0. The Finite Volume Method (FVM) was used to solve the partial differential equations by discretized the equations using an upwind differencing scheme over the finite volumes. The SIMPLE algorithm was used to adjust the pressure and velocities after each iteration when solve the gas continuity and momentum equations. The calculations were conducted on the High Performance Computer (HPC) Peregrine1 (56 Gbps Infiniband interconnects, 8.4 TeraFLOPS) with 80 processors at Purdue University Calumet. 
Numerical Study of a Tangentially Fired Boiler for Reducing Steam Tube Overheating

\section{Geometry and Conditions}

\subsection{Computational Domain}

Geometric model has been developed based on the drawings of boiler structure, which is shown in Figure 1. Steam tubes are distributed on the sidewalls and water running through the tubes are heated or vaporized for electricity generation and various purposes. In this simulation, the steam tubes are simplified as solid adiabatic walls and the wall temperature will represents the steam tube temperature. Three different fuel streams are feed to the four corners from the burners which shown in Figure 2. The cross section in the combustion zone is shown in Figure 3. Fuels come in from the burner ports, and then create a counter-clockwise thermo-flow pattern of recirculation. The fuels ports are Blast Furnace Gas (BFG), Coke Oven Gas (COG) and Natural Gas (NG). COG and NG inlets are partially surrounded by air inlets, producing a diffusion-like flame. "Hopper", the bottom geometry, has slops of 15 degree tilted angle from the horizontal surface and a small opening.

\subsection{Simulation Conditions}

The solution to a flow problem coupled with heat transfer and chemical reactions by using the Finite Volume Method (FVM) is obtained at the nodes inside of each cell or grid. The accuracy of a CFD results is governed by the amount of cells. [37] In addition, grid refinement can reduce the false diffusion effect in numerical simulation especially in simulating a tangentially fired boiler. In this paper, in order to achieve accurate simulation results, mesh sensitivity study was conducted between a 5 million cells grid and a 6 million cells grid, which shows no difference. Therefore, the 5 million cells grid was used to conduct the following simulation as to save some computational time. This simulation is based on the real operation conditions of a certain tangentially fired boiler. The boundary conditions and fuel properties are taken directly from the operation database.

Based on the composition of the fuels, the chemical mechanisms are referred from the ANSYS Fluent database which is shown in Table1. The fuel properties are shown in Table2.

\section{Results and discussions}

\subsection{Validation}


In order to validate CFD model, field experiments were conducted. Under different operation conditions, distinctive flow characteristics and flame profiles were captured by video camera. Therefore, the developed CFD model applied these two different operation conditions and compared the results with field experiments. The boundary conditions of these two different situations were listed in Table 3. The turbulence boundary conditions were defined based on the inlets intensity and hydraulic diameters. The two different cases have different fuel composition and total energy input.

Field experimental videos of the two different cases are shown in Figure 4. The flow characteristics and flame profiles are distinctively different. Simulation works based on the developed CFD model of these two cases are also conducted. The results are post-processed by using software Tecplot and ParaView to visualize the flow characteristics and flame profiles. Temperature contours and streamlines were also post-processed as shown in Figure 5. Temperature contours at the center level of the combustion zone are shown in Figure 6. CO species iso-surface when the mass fraction equals to 0.01 is showing in Figure 7, which could represent the flame shape.

According to Figure 4, the top view of combustion zone indicates that the difference of the flow characteristics and flame profiles are distinctive under two different operating boundary conditions. For high total fuel input Case1, the flames originated from four corners connect with each other and form a strong circulation in the boiler. However, for the lower total fuel input Case2, the flames are sticking to the walls. Comparing to the Case1, the flame vertex actual tangential circle diameter of Case 2 is bigger, which means the circulation formed in the center is less strong than Case 1.

The actual tangential circle diameter is a very important parameter to evaluate the flow properties inside of a tangentially fired boiler. And which can be calculated in the following equation:

$$
d=\frac{\frac{d_{1}}{A}+\frac{d_{2}}{B}}{2}
$$

Figure 5 shows the flow streamlines of these two different situations got from the developed CFD model. The streamlines are colored by temperature. It can be seen from the streamlines that the 
circulation strength and flow directions are different. For Case1, the strong flow circulation was formed at the center of the boiler where the high temperature flames were also stay away from the wall. However, for Case2, the high temperature streamlines are directed to the walls. These two different situations are agreed well with the video captures in Figure 4. The actual tangential circle diameters can be read from Figure 8 according to peer's research [4]. The actual tangential circle diameter of Case 1 is smaller than Case 2 with high peak tangential velocities are closer to the center on $\mathrm{x}$ and $\mathrm{z}$ directions shown in Figure 8 .

The temperature contours in Figure 6 indicate the flame positions at the center level of the combustion zone. For Case1 with higher input momentum, the high temperature flames are around the cold fuel streams shown in Figure 6. Some of the high temperature flames are directed to the burner, which match with the field video. For Case 2 with lower input momentum, the high temperature combustion flames are moving towards the walls. The flame profiles are represented by the species CO concentration. [38-39] Species CO mass fraction 0.01 was used to represent the flame outlines. The difference of the flame profiles under these two different operation conditions can be read in Figure 4. Results for the CFD model are post-processed in Figure 7 which agrees with the field video captures. Therefore, the developed CFD model is validated by comparing the simulation results with field experimental video under different operation conditions.

\subsection{Overheating Phenomena}

\subsubsection{Overheating Position}

By using the validated CFD model, the impact of flames on the steam tubes which simplified as adiabatic walls has been simulated. This simplification would lead to the temperature on the wall higher than the real situation, but can predict trend of the overheating problem. The temperature contours at the front wall and left wall are shown in Figure 9.

Figure 9 shows the temperature contours at the front and left side walls, which indicate a steam tube overheating phenomena in this tangentially fired boiler. There are two major hot spots on each side of the wall, one is near the burner in the combustion zone and the other is above the combustion zone. The hot spots are approximately $100 \mathrm{~K}$ higher than other places. Long time hot spots affect the steam tubes and this temperature deviation would cause the tube failure accidents 
in the real operation. Based on previous research work and industrial feedback, under different operation conditions, the steam tube failure places are similar and agree with the CFD results.

\subsubsection{Hot Spot Definition}

A group of typical operation conditions with power output ranges from $100 \mathrm{MW}$ to $200 \mathrm{MW}$ were evaluated by using the validated CFD model. These typical operation conditions are listed in Table 4. Eleven operation conditions were selected which shown different hot spots temperatures. The first five cases have higher wall average temperature and peak temperature than the other six cases, which shown in Figure 10.

According to Figure 10, the maximum difference between Case 2 and Case10 on the average wall temperature is around $100 \mathrm{~K}$. And the average wall temperature of the first five cases is higher than the other cases. Compare to the average temperature on the wall, the peak temperature would have more effect on the steam tube overheating problems. The long time temperature deviation on the steam tube with high hot spot peak temperature impingement increases the risk of steam tube failure greatly. It can be seen that the maximum difference of peak temperature among all the operation cases is approximately $150 \mathrm{~K}$. All the cases are under the typical operation conditions which covered most of the situations. As some of the typical operation conditions do not lead to serious steam tube failure problem, which would be considered as safe situation. While some other cases did cause overheating problems. Therefore, the temperature between $750 \mathrm{~K}$ and $900 \mathrm{~K}$ on the steam tubes would be harmful to the steam tubes life, which is defined as a hot spot in this simulation.

\subsubsection{Hot Spot Area}

Based on the definition of the hot spot on the steam tube, the area of the hot spot was clipped by setting up the temperature range from $750 \mathrm{~K}$ to $900 \mathrm{~K}$. The hot spot area also has a great effect on the steam tubes. Long time exposed with hot spot, the steam tube would suffer the imbalance of stress forces and lead to the steam tube failure problems. The hot spot areas under different operation conditions are shown in Figure 11. 
According to Figure 11, the hot spot area under different operation conditions appears different. The first five cases have larger hot spot area than the other cases. The differences of hot spot area appear dramatically big between the Case 2 and Case 10, which represent for the risk and safe operation conditions, respectively.

Therefore, in terms of steam tube overheating problem, there are two criteria to judge the extent of impact on the steam tubes, one is the peak temperature and the other is area of the hot spots. When reducing the hot spots peak temperature to a certain degree which the steam tube steel can stand, the risk of steam tube failure problems will be reduced. If the hot spots area can be further reduced, the risk of steam tube failure will be further reduced. This hot spot area and peak temperature will be used as judgments on safe and risk operation conditions.

\subsection{Parametric studies}

In order to optimize the operation of the tangentially fired boiler firing metallurgical gases to get rid of steam tube failure problems, a further study on optimizing operation parameters was conducted. Based on previous study on a great amount of cases under different operation conditions, the effects of total fuel input and the NG percentage were investigated.

\subsubsection{Effect of Total Fuel Input}

Tangentially fired boilers in steel mills are always under different fuel input loads at different time according to their demands. Under different fuel loads, the combustion processes and flow characteristics are shown different according to the validation cases. And the impact on the steam tube overheating problems would be different. Therefore, a study on the effect of different fuel input loads on the steam tube overheating is necessary.

Based on the real operation conditions of the tangentially fired boiler in one steel mill, three different fuel input loads are applied to investigate the effects on the flow characteristics and overheating problems. The boundary conditions are shown in Table 5.

The total fuel input loads has great effect on the combustion process and side wall temperature distributions. The temperature contours at the natural gas inlet level for three different fuel input 
load cases are shown in Figure 12. The side walls peak temperature and hot spots area are plotted in Figure 13 (a) and (b).

It can be seen from Figure 12 that different fuel input loads have great effect on the flow characteristics and temperature field. The temperature contour of the low load fuel input shows that the fuel input under this condition could not help to form a tangentially circulated flame in the center. Meanwhile, the high temperature flames are directed to the wall near the burner, which would cause some overheating problems. After further increasing the fuel input load, the input fuels can form a strong circulated circle in the center of the boiler and combustion mainly occurred around the circle. The formed tangential circle can help to improve the combustion process and also avoid the flame impingement phenomenon. When further increase the fuel input load, the tangential flow circle show similar pattern with higher combustion temperature in the circle and center.

According to Figure 13, with the increasing of fuel input load, the peak temperature at the side wall firstly decreases and then increases. However, the side wall peak temperature at the low load fuel input condition even higher than the high load fuel input condition, which is due to the flame impingement under low load fuel input when a tangential combustion circle can not be formed. Meanwhile, when the fuel and air streams form a tangential circle, the further increasing of fuel input will lead to increasing of side wall peak temperature. In addition, with the increase of fuel input load, the hot spot area on the side walls is also first decrease and then increase, which shows similar trend with side wall peak temperature. Under this criterion, the case with medium fuel input but can form a strong circulation in the boiler is benefit for the boiler operations and can help to reduce its risk of steam tube failure problems.

\subsubsection{Effect of NG Percentage}

For this particular boiler mainly firing metallurgical gases, the NG input percentage has a great effect on the side wall temperature in the combustion zone. According to its operation conditions, exceed of $10 \%$ NG input would not applicable during the field operation. Therefore the effect of NG input percentage from $0 \%$ to $10 \%$ was conducted under the high fuel input load condition. 
Based on the validated CFD model, the simulation was conducted under the six different operation conditions. The effect of NG input percentage on the side wall temperatures and hot spot areas in the combustion zone has been analyzed based on the results. The results are plotted in Figure 14. With the increase of NG percentage, the average temperature on two side walls and the peak temperature in the hot spots are firstly decreased and then increased. $2 \%$ of NG input case has lowest peak temperature among other cases. The hot spot temperature has a difference about 100K between 2 percent input and 10 percent NG input boundary conditions. For the hot spot area, from 0 percent to 10 percent NG input, it decreased form $1.7763 \mathrm{~m}^{2}$ to $1.1571 \mathrm{~m}^{2}$ and then increased to $13.4787 \mathrm{~m}^{2}$ rapidly. Therefore, a suggest NG input percentage at the high load operation conditions should be around $2 \%$.

\section{Conclusions}

A detailed three-dimensional computational fluid dynamics model for an industrial tangentially fired boiler firing metallurgical gases was developed. Eddy dissipation concept turbulence combustion model was used to solve the turbulence flow with combustion. The model was validated by comparing the model predicted flame profiles to the real operation video capture under different operation conditions. The simulation results showed hot spots on the furnace wall. The hot spot temperature and area are determined based on investigating a wide range of operating conditions. The parametric study results suggested that total fuel input has great effect on the steam tube overheating problems. Proper total fuel input would help to form a strong circulation in the tangentially fired boiler to avoid flame impingement on the steam tube. Natural gas input has significant effect on the wall temperature, and 2 percent (volume) is the optimal value for operation to avoid overheating problem.

\section{Acknowledgments}

The authors would like to thank ArcelorMittal USA for offering this research opportunity, providing funding, and for assistance during the course of this work. The authors would also like to thank the Center for Innovation through Visualization and Simulation (CIVS) at Purdue University Calumet for providing all the resources required for this work. 
This research was partially supported by U.S. Department of Energy Grant DE-NA000741 under the administration of the National Nuclear Security Administration.

\section{Nomenclatures}

$A \quad$ Width of the tangentially fired boiler at a certain cross-section area

$B \quad$ Length of the tangentially fired boiler at a certain cross-section area

C Linear-anisotropic phase function coefficient

$p \quad$ Static pressure, pascal

$\rho \quad$ Density, $\mathrm{kg} / \mathrm{m}^{3}$

$\overline{\mathrm{F}} \quad$ External body force, $\mathrm{N}$

$S_{m} \quad$ Mass added to the continuous phase from the dispersed second phase (e.g., due to vaporization of liquid droplets) and any user-defined sources

$\bar{g} \quad$ Gravity, $\mathrm{m} / \mathrm{s}^{2}$

$\overline{\bar{\tau}} \quad$ Stress tensor

$\mu \quad$ Molecular viscosity, $\mathrm{kg} \cdot \mathrm{m} / \mathrm{s}$

I Unit tensor

$\mathrm{k}_{\text {eff }} \quad$ Effective conductivity, w/m-K

$h_{j} \quad$ Sensible enthalpy of species j

$\vec{J}_{j} \quad$ Diffusion flux of species $\mathrm{j}$

$S_{h} \quad$ Heat of chemical reaction, and any other volumetric heat sources, J

$k \quad$ Turbulence energy, $\mathrm{m}^{2} / \mathrm{s}^{2}$

$\sigma_{i j} \quad$ Stress tensor due to molecular viscosity

$\epsilon \quad$ Turbulent dissipation rate $\mathrm{m}^{2} / \mathrm{s}^{3}$

$\sigma_{\mathrm{k}} \quad$ Turbulent Prandtl number for $k, 1.0$

$\sigma_{\varepsilon} \quad$ Turbulent Prandtl number for $\epsilon, 1.2$

$\mu_{t} \quad$ Turbulence viscosity, $\mathrm{kgm} / \mathrm{s}$

$\beta \quad$ Thermal expansion coefficient $\mathrm{K}^{-1}$

$\vec{v} \quad$ Velocity, $\mathrm{m} / \mathrm{s}$

$u_{j} \quad$ Velocity component along the direction $\mathrm{x}_{\mathrm{j}}, \mathrm{m} / \mathrm{s}$

$u_{i}^{\prime} \quad$ instant turbulence velocity on the direction $\mathrm{x}_{\mathrm{i}}, \mathrm{m} / \mathrm{s}$ 
$G_{k} \quad$ Generation of turbulence kinetic energy due to the mean velocity gradients, $\mathrm{m}^{2} / \mathrm{s}^{2}$

$c_{\mu} \quad$ Constant

$\mathrm{Pr}_{t} \quad$ Turbulent Prandtl number for energy

$g_{i} \quad$ Component of the gravitational vector in the $i$ th direction, $\mathrm{m} / \mathrm{s}^{2}$

$G_{b} \quad$ Generation of turbulence kinetic energy due to buoyancy, $\mathrm{m}^{2} / \mathrm{s}^{2}$

$Y_{M} \quad$ Contribution of the fluctuating dilatation in compressible turbulence to the overall dissipation rate

$S \quad$ Modulus of the mean rate-of-strain tensor

$S_{K} \quad$ User defined source term

$S_{\varepsilon} \quad$ User defined source term

$\mathrm{C}_{1 \varepsilon} \quad$ Constant, 1.44

$\mathrm{C}_{2} \quad$ Constant, 1.9

$d_{1} \quad$ Intervals between maximum tangential velocities width directions

$d_{2} \quad$ Intervals between maximum tangential velocities length directions

a Absorption coefficient, $\mathrm{m}^{-1}$

$n \quad$ Refractive index

$\sigma_{s} \quad$ Scattering coefficient, $\mathrm{m}^{-1}$

$\sigma \quad$ Stefan-Boltzmann constant $\left(5.67 \times 10^{-8} \frac{W}{m^{2} K^{4}}\right)$

T Local temperature, $\mathrm{K}$

$Y_{i} \quad$ Local mass fraction of each species

$C_{p, j} \quad$ Constant pressure specific heat of species $\mathrm{j}$

$R_{i} \quad$ Net rate of production of species $i$ by chemical reactions

$\overrightarrow{J_{l}} \quad$ Diffusion flux term of species $i$

$D_{i, m} \quad$ Diffusion coefficient for specie $i$ in the mixture

$D_{T, i} \quad$ Thermal diffusion coefficient

$S c_{t} \quad$ Turbulent Schmidt number, 0.7

$Y_{i}^{*} \quad$ Mass fraction of species $i$ within the fine structures after reacting over the time $\tau^{*}$

$Y_{i}^{0} \quad$ Mass fraction of species $i$ in the fluid surrounding the fine structures

$\xi^{*} \quad$ Mass fraction occupied by the fine structure regions

$C_{\xi} \quad$ Volume fraction constant, 2.1377 
Numerical Study of a Tangentially Fired Boiler for Reducing Steam Tube Overheating

Kinematic viscosity $\mathrm{m}^{2} / \mathrm{s}$

\section{References}

1. X. Xu, Z. Wang, Y. Zhuo, C. Zheng, False diffusion in numerical simulation of combustion processes in tangential-fired furnace, Journal of Mechanical Science and Technology 21 (2007) 1828-1846.

2. M.A. Habib, R. Ben-Mansour, H.I. Abualhamayel, Thermal and emission characteristics in a tangentially fired boiler model furnace, Int.J.Energy Res. 34 (2010) 1164-1182.

3. Y. Zhou, T. Xu, S. Hui, M. Zhang, Experimental and numerical study on the flow fields in upper furnace for large scale tangentially fired boilers, Applied Thermal Engineering 29 (2009) 732-739.

4. Y. Zhou, M. Zhang, T. Xu, S. Hui, Effect of opposing tangential primary air jets on the flue gas velocity deviation for large-scale tangentially fired boilers, Energy \& fuels 23(2009) 5375-5382.

5. B. He, M. Chen, S. Liu, L. Fan, J. Xu, W. Pan, Measured vorticity distributions in a model of tangentially fired furnace, Experimental Thermal and Fluid Science 29 (2005) 537-554.

6. S. Belosevic, M. Sijercic, S. Oka, D. Tucakovic, "Three-dimensional modeling of utility boiler pulverized coal tangentially fired furnace, International Journal of Heat and Mass Transfer 49 (2006) 3371-3378.

7. R. Vuthaluru, H.B. Vuthaluru, Modelling of a wall fired furnace for different operating conditions using Fluent, Fuel Processing Technology 87 (2006) 633-639.

8. S. Belosevic, M. Sijercic, N. Crnomarkovic, B. Stankovic, Numerical Prediction of Pulverized Coal Flame in Utility Boiler Furnaces, Energy Fuel 23 (2009) 5401-5412.

9. C. Yin, L. Rosendahl, T.J. Gondra, Further study of the gas temperature deviation in large-scale tangentially coal-fired boilers, Fuel 82 (2003) 1127-1137.

10.C. Yin, S. Caillat, J. Harion, B. Baudoin, E. Perez, Investigation of the flow, combustion, heat-transfer and emissions from a 609MW utility tangentially fired pulverized-coal boiler, Fuel 81 (2002) 997-1006.

11.H.B. Vuthaluru, R. Vuthaluru, Control of ash related problems in a large scale tangentially fired boiler using CFD modeling, Applied Energy 87 (2010) 1418-1426.

12.Z.W. Liu, S, Zheng, Z.X. Luo, H.C. Zhou, A new method for constructing radiative energy signal in a coal-fired boiler, Applied Thermal Engineering, DOI: http://dx.doi.org/doi: 10.1016/j. applthermaleng. 2016.01.034.

13.A. Ryfa, R. Buczynski, M. Chabinski, A. Szlek, Decoupled numerical simulation of a solid fuel fired retort boiler, Applied Thermal Engineering, 73 (2014) 794-804. 
14.S. Belosevic, I. Tomanovic, N. Crnomarkovic, A. Milicevic, D. Tucakovic, Numerical study of pulverized coal-fired utility boiler over a wide range of operating conditions for in-furnace $\mathrm{SO} 2 / \mathrm{NOx}$ reduction, Applied Thermal Engineering, 94 (2016) 657-669.

15.S.S. Hou, C.H. Chen, C.Y. Chang, C.W. Wu, J.J. Ou, T.H. Lin, Firing blast furnace gas without support fuel in steel mill boilers, Energy Conversion and Management 52 (2011) 2758-2767.

16.H.K. Ma, F.S. Wu, Effect of BFG on unburned carbon formation in a coal-fired boiler, International Communications in Heat Mass Transfer 19 (1992) 409-421.

17.C. Bojic, P. Mourdoukountas, Energy saving does not yield CO2 emissions reductions: the case of waster fuel use in a steel mill, Appl. Therm. Eng. 20 (2000) 963-975.

18. S. Shieh, Y. Chang, S. Jang, M. Ma, T. Huang, Statistical key variable analysis and model-based control for the improvement of thermal efficiency of a multi-fuel boiler, Fuel 89 (2010) 1141-1149.

19.O. Gicquel, L. Vervisch, G. Joncquet, B. Labegorre, N. Darabiha, Combustion of residual steel gases: laminar flame analysis and turbulent flamelet modeling, Fuel 82(8) (2003) 983-991.

20.K. Kawai, K. Yoshikawa, H. Kobayashi, J. Tsai, M. Matsuo, H. Katsushima, High temperature air combustion boiler for low BTU gas, Energy Conversion and Management 43 (2002) 1563-1570.

21.C.L. Lee, S.S. Hou, W.J. Lee, C.G. Jou, Improving cost-effectiveness for the furnace in a full-scale refinery plant with reuse of waste tail gas fuel, International Journal of Hydrogen Energy 35 (2010) 1797-1802.

22.M. Bojic, P. Mourdoukoutas, Energy saving does not yield $\mathrm{CO}_{2}$ emissions reductions: the case of waste fuel use in a steel mill, Applied Thermal Engineering 20 (2000) 963-975.

23.X. Paubel, A Cessou, D. Honore, L. Vervisch, R. Tsiava, A flame stability diagram for piloted nonpremixed oxycombustion of low calorific residual gases, Proceedings of the Combustion Institute 31 (2007) 3385-3392.

24.L. Shi, Z.G. Fu, X.N. Duan, C.Y. Cheng, Y.Z Shen, B.H Liu, R.X. Wang, Influence of combustion system retrofit on NOx formation characteristics in a 300 MW tangentially fired furnace, Applied Thermal Engineering 98(2016) 766-777.

25.G.K. Liu, Z.C. Chen, Z.Q. Li, G.P. Li, Q.D. Zong, Numerical simulations of flow, combustion characteristics, and NOx emission for down-fired boiler with different arch-supplied over-fire air ratios, Applied Thermal Engineering 75 (2015) 1034-1045.

26. M. Yang, Y.Y. Shen, H.T. Xu, M. Zhao, S.W. Shen, K. Huang, Numerical investigation of the nonlinear flow characteristics in an ultra-supercritical utility boiler furnace, Applied Thermal Engineering 88 (2015) 237-247.

27.H.Y. Kim, S.W. Baek, S.W. Kim, Investigation of fuel lean reburning process in a $1.5 \mathrm{MW}$ boiler, Applied Energy 89 (2012) 183-192. 
28. A. Parente, C. Galletti, L. Tognotti, Effect of the combustion model and kinetic mechanism on the MILD combustion in an industrial burner fed with hydrogen enriched fuel, International Journal of Hydrogen Energy 33 (2008) 7553-7564.

29.L.K. Hjertager, J. Osenbroch, B.H. Hjertager, T. Solberg. "Validation of the eddy dissipation concept for fast chemical reactions in turbulent liquid flows", Chemical Reaction Engineering VII: CFD, 6-11 August, 2000 Quebec City, Canada.

30.L.K. Hjertager, B.H. Hjertager, T. Solberg. "CFD modeling of fast chemical reactions in turbulent liquid flows", Computers \&Chemical Engineering, 2002, 26(4): 507-515.

31.ANSYS Fluent 13.0, Theory Guide, ANSYS, Inc. 2010.

32.C.L. Yeh, Numerical investigation of the heat transfer and fluid flow in a carbon monoxide boiler, International Journal of Heat and Mass Transfer 55 (2012) 3601-3617.

33.T.H. Shih, W.W. Liou, A. Shabbir, J. Zhu, A new k- $\varepsilon$ eddy-viscosity model for high Reynolds number turbulent flows-model development and validation, Comput. Fluids 14(3) (1995) 227-238.

34.M. Graca, A. Duarte, P.J. Coelho, M. Costa, Numerical Simulation of a Reversed Flow Small-scale Combustor, Fuel Processing Technology 107 (2013) 126-137.

35.M.A. Habib, R.B. Mansour, M.A. Antar, Flow field and thermal characteristics in a model of a tangentially fired furnace under different conditions of burner tripping, Heat Mass Transfer 41 (2005) 909-920.

36.D.J.O. Ferreira, M. Cardoso, S.W. Park, The impact of radiation on gas combustion modeling for a kraft recovery boiler, $11^{\text {th }}$ International Symposium on Process Systems Engineering 15-19 July 2012, Singapore.

37.H.K. Versteeg, W. Malalasekera, An introduction to Computational Fluid Dynamics, the finite volume method, Prentice-Hall, Essex, UK, 2007.

38.G. Tang, B. Wu, K. Johnson, A. Kirk, C.Q. Zhou, Simulation of an industrial tangentially fired boiler firing metallurgical gases, J. Thermal Sci. Eng. Appl 7(1) 011003, 2014, doi: 10.1115/1.4028344.

39. C.E. Baukal, The Jonh Zink Hamworthy Combustion Handbook, Volume 1, Fundamentals, Second edition, Taylor \& Francis Group, LLC, 2013. 
Numerical Study of a Tangentially Fired Boiler for Reducing Steam Tube Overheating

39. C.E. Baukal, The Jonh Zink Hamworthy Combustion Handbook, Volume 1, Fundamentals, Second edition, Taylor \& Francis Group, LLC, 2013. 


\section{List of Tables}

Table 1 Reaction Mechanisms

Table 2 Fuel Species Compositions

Table 3 Boundary conditions

Table 4 Boundary conditions of the typical operation conditions

Table 5 Different input fuel load boundary conditions 
Table 1 Reaction Mechanisms

\begin{tabular}{cc}
\hline Fuel & Global chemical reaction \\
\hline Methane & $1 \mathrm{CH}_{4}+\frac{3}{2} \mathrm{O}_{2} \rightarrow 1 \mathrm{CO}+2 \mathrm{H}_{2} \mathrm{O}$ \\
& $1 \mathrm{CO}+\frac{1}{2} \mathrm{O}_{2} \rightarrow 1 \mathrm{CO}_{2}+0 \mathrm{H}_{2} \mathrm{O}$ \\
Hydrogen & $1 \mathrm{H}_{2}+\frac{1}{2} \mathrm{O}_{2} \rightarrow 1 \mathrm{H} 2 \mathrm{O}$ \\
Ethane & $1 \mathrm{C}_{2} \mathrm{H}_{6}+\frac{7}{2} \mathrm{O}_{2} \rightarrow 2 \mathrm{CO}_{2}+3 \mathrm{H}_{2} \mathrm{O}$ \\
Ethylene & $1 \mathrm{C}_{2} \mathrm{H}_{4}+3 \mathrm{O}_{2} \rightarrow 2 \mathrm{CO}_{2}+2 \mathrm{H}_{2} \mathrm{O}$ \\
\hline
\end{tabular}


Table 2 Fuel Species Compositions

\begin{tabular}{llll}
\hline Species & BFG & COG & NG \\
\hline $\mathrm{O}_{2}$ & & 0.004 & \\
$\mathrm{~N}_{2}$ & 0.47 & 0.04 & \\
$\mathrm{C}_{2} \mathrm{H}_{6}$ & & 0.008 & 0.029 \\
$\mathrm{C}_{2} \mathrm{H}_{4}$ & & 0.022 & \\
$\mathrm{CH}_{4}$ & & 0.253 & 0.944 \\
$\mathrm{CO}_{2}$ & 0.25 & 0.026 & 0.027 \\
$\mathrm{CO}$ & 0.22 & 0.05 & \\
$\mathrm{H}_{2}$ & 0.06 & 0.597 & \\
$\mathrm{H}_{2} \mathrm{O}$ & & & \\
\hline
\end{tabular}


Numerical Study of a Tangentially Fired Boiler for Reducing Steam Tube Overheating

Table 3 Boundary conditions

\begin{tabular}{cccc}
\hline Cases & $\begin{array}{c}\text { Case1 } \\
(\mathrm{m} / \mathrm{s})\end{array}$ & $\begin{array}{c}\text { Case2 } \\
(\mathrm{m} / \mathrm{s})\end{array}$ & $\begin{array}{c}\text { Temperature } \\
(\mathrm{K})\end{array}$ \\
\hline Air inlet & 25.6 & 21.96 & 349.80 \\
Coke Oven Gas inlet & 16.55 & 19.39 & 298.70 \\
Blast Furnace Gas inlet & 3.92 & 7.28 & 310.93 \\
Natural Gas inlet & 173.48 & 46.59 & 295.37 \\
& & & \\
\hline
\end{tabular}


Table 4 Boundary conditions of the typical operation conditions

\begin{tabular}{ccccc}
\hline Cases & $\begin{array}{c}\text { BFG } \\
(\mathrm{m} / \mathrm{s})\end{array}$ & $\begin{array}{c}\text { COG } \\
(\mathrm{m} / \mathrm{s})\end{array}$ & $\begin{array}{c}\mathrm{NG} \\
(\mathrm{m} / \mathrm{s})\end{array}$ & $\begin{array}{c}\text { Air } \\
(\mathrm{m} / \mathrm{s})\end{array}$ \\
\hline 1 & 8.37 & 14.33 & 155.66 & 23.89 \\
2 & 12.55 & 0 & 202.58 & 20.07 \\
3 & 4.28 & 7.34 & 79.49 & 20.07 \\
4 & 10.46 & 17.92 & 194.56 & 23.89 \\
5 & 8.01 & 0 & 129.02 & 23.89 \\
6 & 17.71 & 15.53 & 115.22 & 22.55 \\
7 & 13.5 & 12.6 & 84.9 & 19.1 \\
8 & 14.5 & 0 & 42.775 & 20.07 \\
9 & 11.6 & 0 & 34.22 & 20.07 \\
10 & 16.63 & 25.87 & 55.84 & 20.07 \\
11 & 13.31 & 20.69 & 44.71 & 20.07 \\
\hline
\end{tabular}


Table 5 Different input fuel load boundary conditions

\begin{tabular}{lllll}
\hline Cases & $\begin{array}{l}\text { BFG } \\
(\mathrm{m} / \mathrm{s})\end{array}$ & $\begin{array}{l}\text { COG } \\
(\mathrm{m} / \mathrm{s})\end{array}$ & $\begin{array}{l}\text { NG } \\
(\mathrm{m} / \mathrm{s})\end{array}$ & $\begin{array}{l}\text { Total Fuel } \\
\text { Input }\end{array}$ \\
\hline 1 & 9.05 & 7.95 & 58.64 & Low Load \\
2 & 13.50 & 12.60 & 84.90 & Medium load \\
3 & 17.71 & 15.53 & 115.22 & High Load \\
\hline
\end{tabular}




\section{List of Figures}

Figure 1 Computational domain

Figure 2 Burner configuration

Figure 3 Cross section of boiler combustion zone

Figure 4 Field inspection of the flow and flame profiles of Case1 (left) and Case2 (right)

Figure 5 Simulation results of flow streamline colored by temperature of Case1 (left) and Case 2 (right)

Figure 6 Temperature contours at the center level of the combustion zone, Case1 (left) and Case 2 (right)

Figure 7 Species CO mass fraction 0.01 iso-surface Case1 (left) and Case2 (right)

Figure 8 Tangential velocity along $\mathrm{x}$ and $\mathrm{z}$ directions at the top of combustion zone for two cases Figure 9 Temperature contours at the front and left side walls

Figure 10 Wall average temperature and peak temperature under different operation conditions Figure 11 Hot spot Area under different operation conditions

Figure 12 Temperature contours at NG inlet level under three different fuel input loads

Figure 13 Front wall temperature contour, (b) Peak temperature and hot spot area under different fuel input loads

Figure 14 Effect of input fuel NG percentage on the side wall peak temperature and hot spot area 
Figure 1

Numerical Study of a Tangentially Fired Boiler for Reducing Steam Tube Overheating

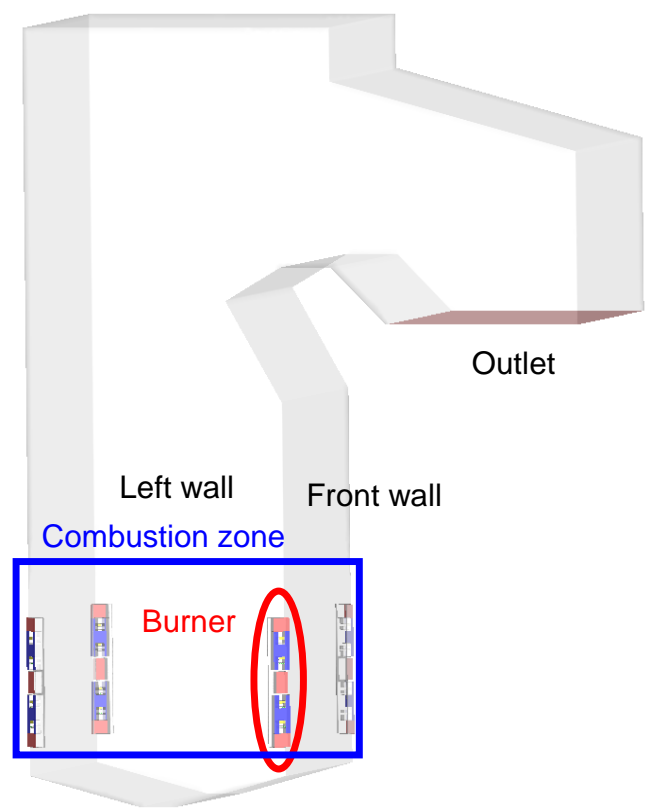

Figure 1 Computational domain 
Figure 2

Numerical Study of a Tangentially Fired Boiler for Reducing Steam Tube Overheating

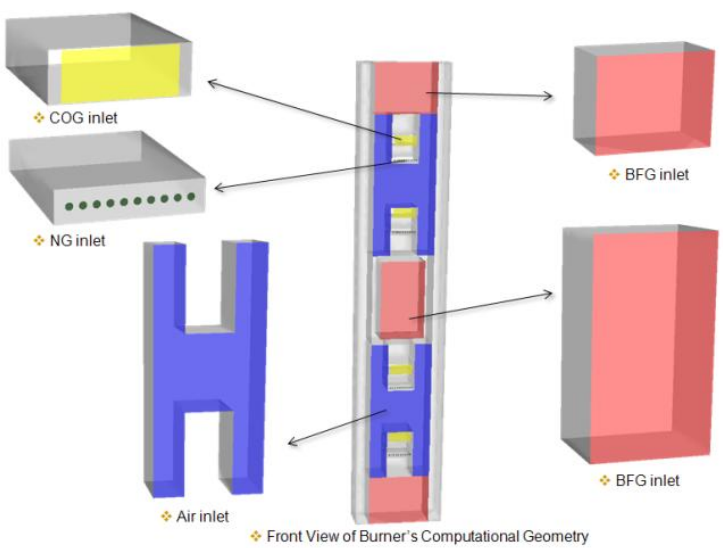

Figure 2 Burner configuration 


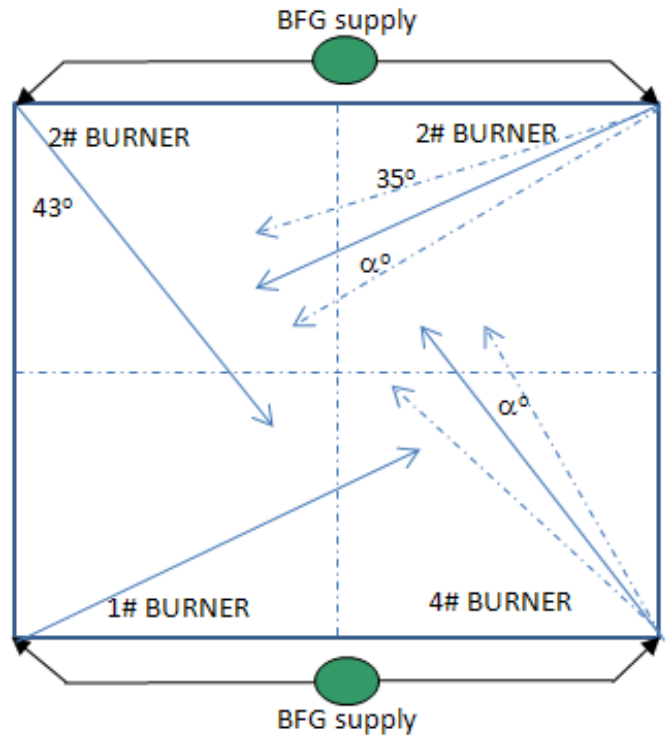

Figure 3 Cross section of boiler combustion zone 
Figure 4

Numerical Study of a Tangentially Fired Boiler for Reducing Steam Tube Overheating
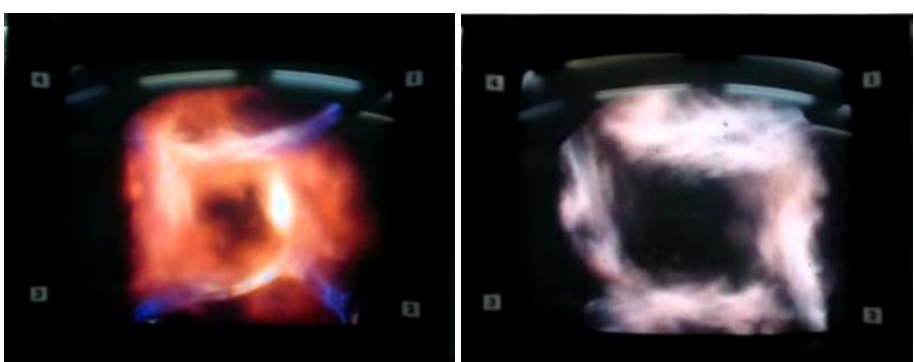

Figure 4 Field inspection of the flow and flame profiles of Case1 (left) and Case2 (right) 
Figure 5

Numerical Study of a Tangentially Fired Boiler for Reducing Steam Tube Overheating
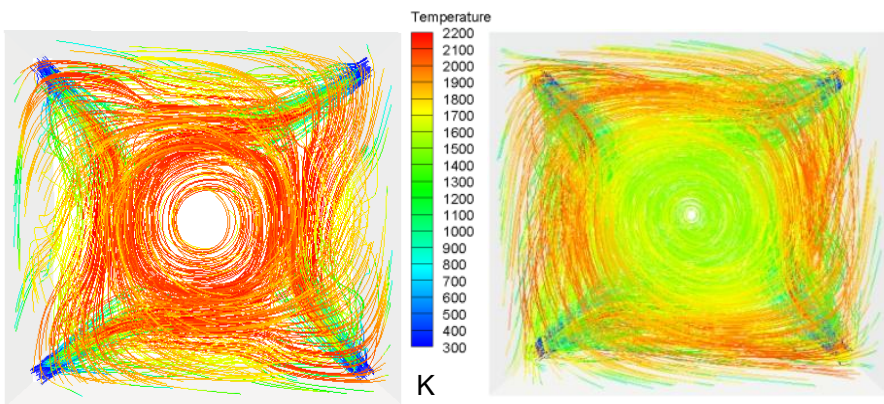

Figure 5 Simulation results of flow streamline colored by

temperature of Case1 (left) and Case2 (right) 
Figure 6

Numerical Study of a Tangentially Fired Boiler for Reducing Steam Tube Overheating

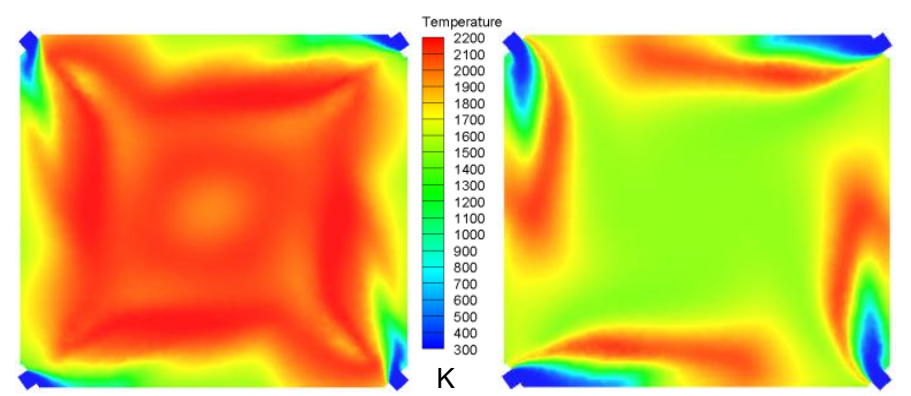

Figure 6 Temperature contours at the center level of the combustion zone, Case1 (left) and Case2 (right) 
Figure 7

Numerical Study of a Tangentially Fired Boiler for Reducing Steam Tube Overheating

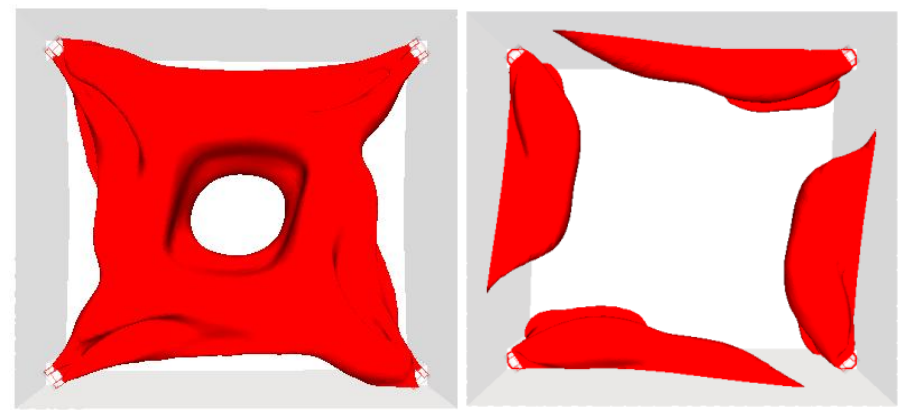

Figure 7 Species CO mass fraction 0.01 iso-surface

Case1 (left) and Case2 (right) 


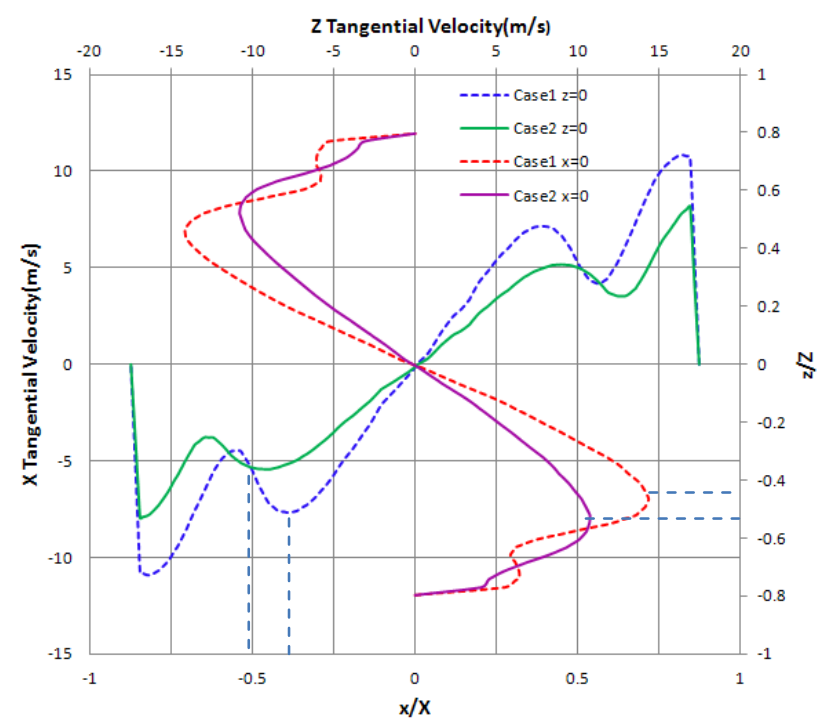

Figure 8 Tangential velocity along $\mathrm{x}$ and $\mathrm{z}$ directions at the top of combustion zone for two cases 


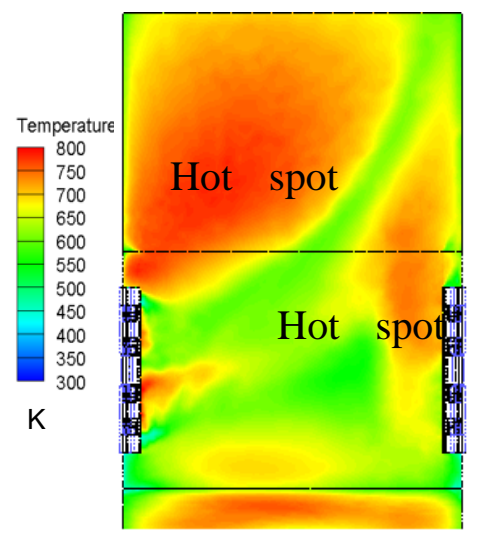

Front Wall

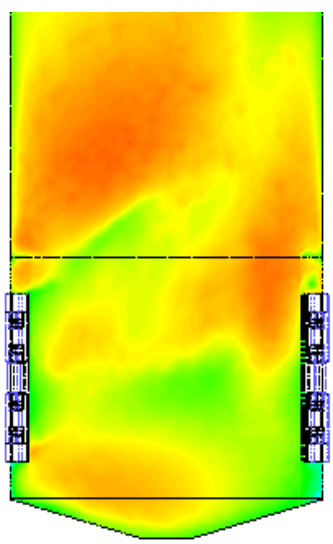

Left

Figure 9 Temperature contours at the front and left side

walls 


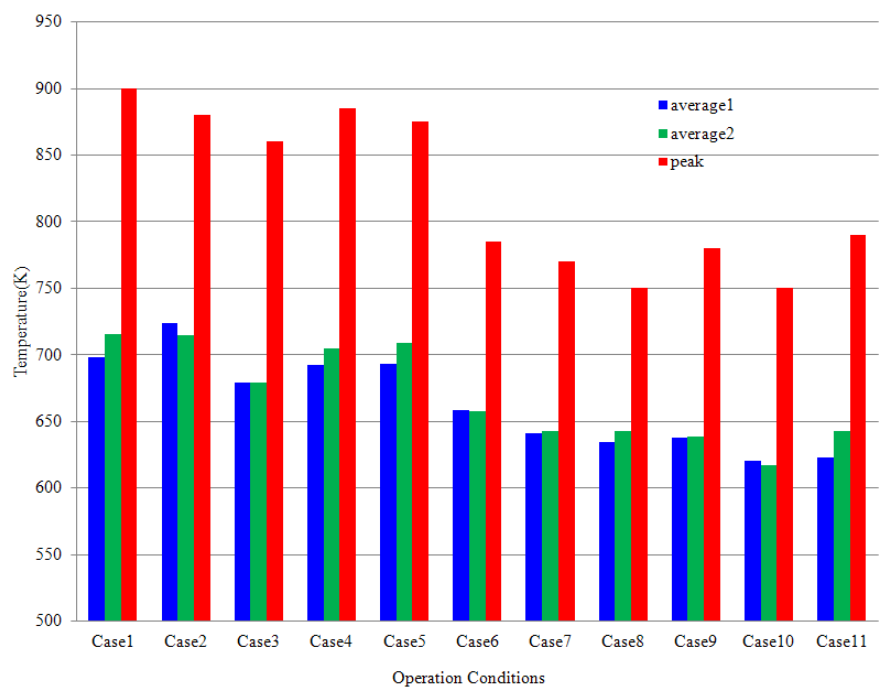

Figure 10 Wall average temperature and peak temperature under different operation conditions 
Figure 11

Numerical Study of a Tangentially Fired Boiler for Reducing Steam Tube Overheating

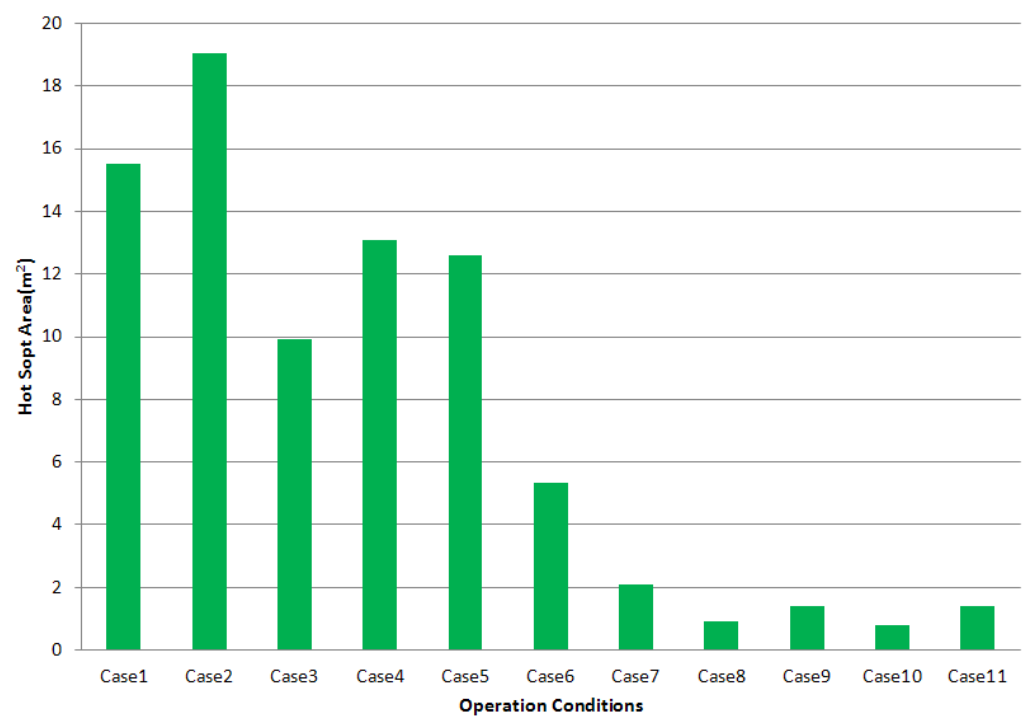

Figure 11 Hot spot Area under different operation conditions 


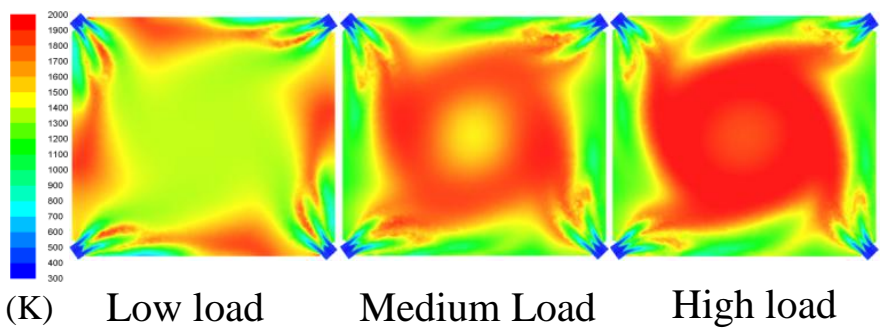

Figure 12 Temperature contours at NG inlet level under three different fuel input loads 
Figure 13

Numerical Study of a Tangentially Fired Boiler for Reducing Steam Tube Overheating

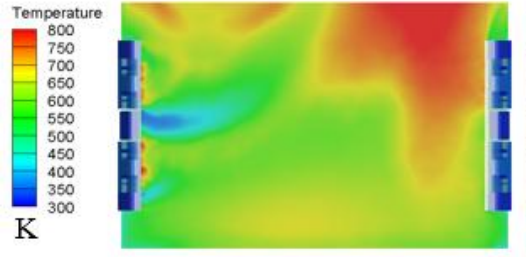

Low load

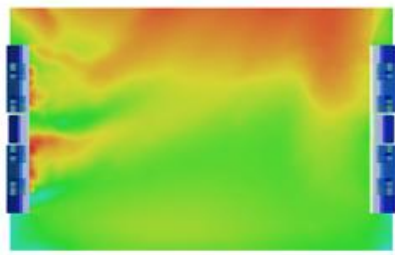

Medium load

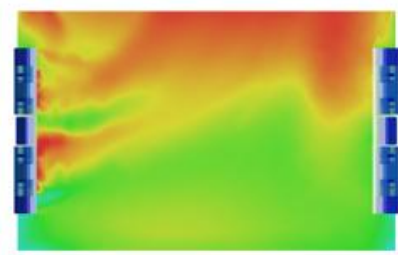

High load

(a)

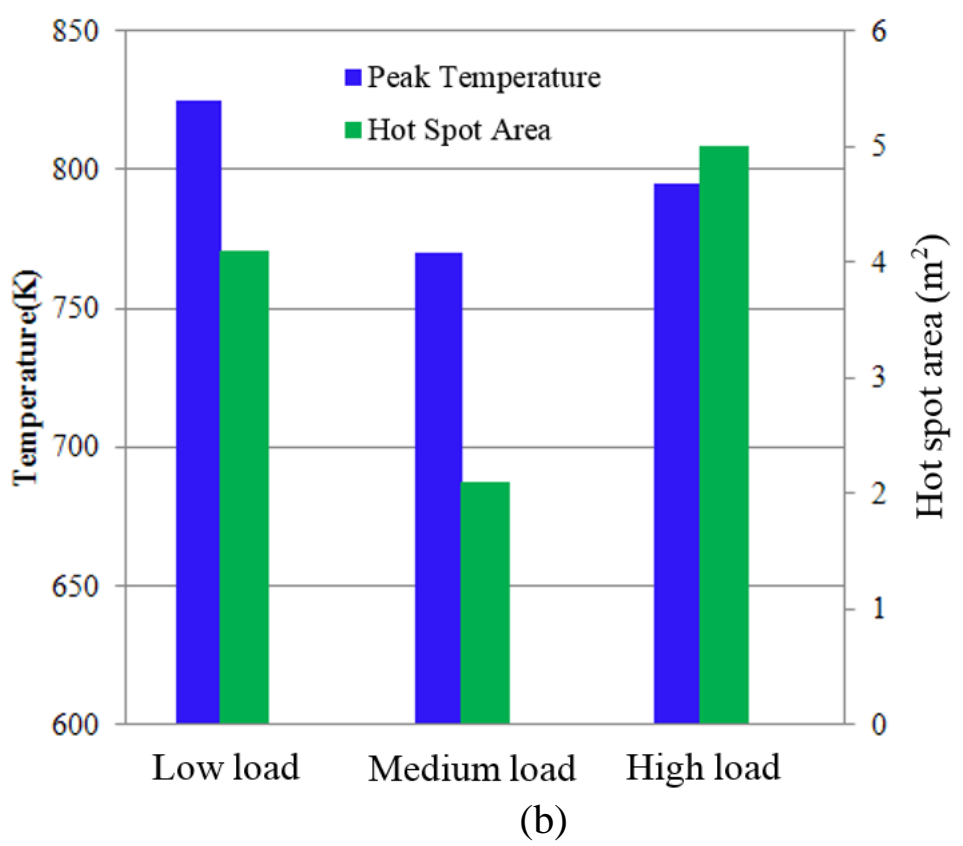

Figure 13 Front wall temperature contour, (b) Peak temperature and hot spot area under different fuel input loads 


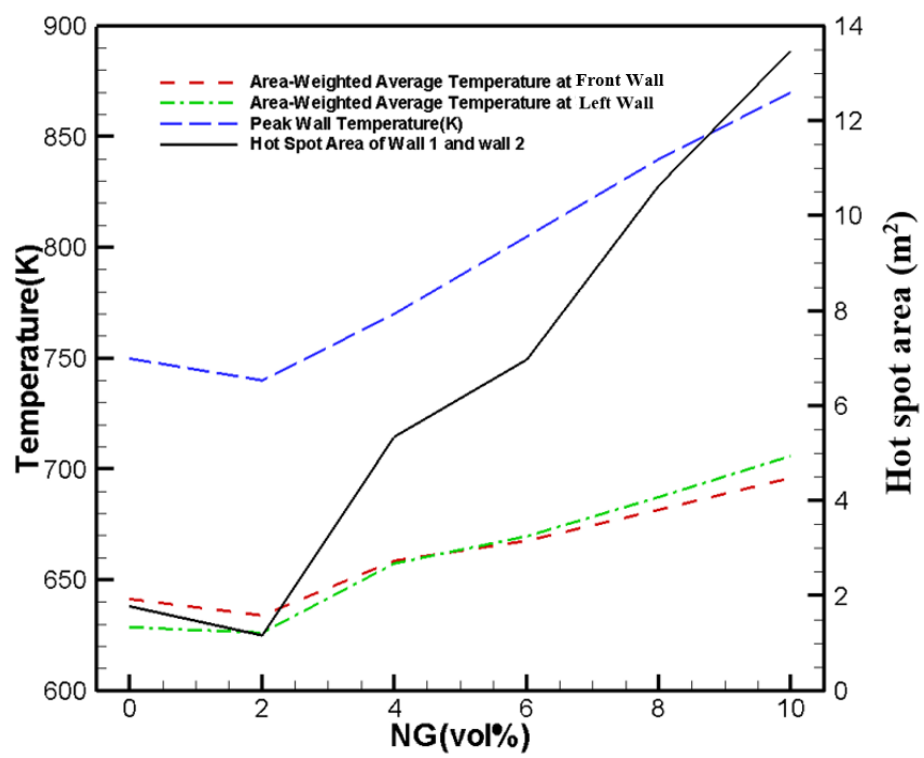

Figure 14 Effect of input fuel NG percentage on the side

wall peak temperature and hot spot area 